\title{
Minimally invasive lateral lumbar interbody fusion with direct psoas visualization
}

\author{
Philip S Yuan', Kasra Rowshan', Rohit B Verma², Larry E Miller ${ }^{3,4}$ and Jon E Block ${ }^{4^{*}}$
}

\begin{abstract}
Background: Minimally invasive lateral approaches to the lumbar spine have been adopted to allow access to the intervertebral disc space while avoiding the complications associated with anterior or posterior approaches. This report describes a minimally invasive technique for lateral lumbar interbody fusion LLIF that allows direct intraoperative visualization of the psoas and surrounding neurovasculature (DV-LIF).

Methods: The technique utilizes a radiolucent tubular retractor and a secondary psoas retractor that allows a muscle-sparing approach while offering excellent visualization of the operative site. The unique advantage of this procedure is that the psoas muscle and surrounding nerves can be directly visualized intraoperatively to supplement neuromonitoring. We retrospectively reviewed complication rates in 34 patients treated with DV-LLIF $(n=19)$ or standard lateral lumbar interbody fusion (S-LLIF, $n=15)$.

Results: There were 29 complications (median: 1 per patient) with DV-LLIF and 20 (median: 1 per patient) complications with S-LLIF. Postoperative sensory deficits were reported in eight (42\%) and seven (47\%) patients, respectively. Thigh pain or numbness was reported in eight (42\%) and five (33\%) patients, respectively. The percentage of the overall complications directly attributable to the procedure was $69 \%$ with DV-LLIF and $83 \%$ with S-LLIF. One severe complication (back pain) was reported in one DV-LLIF patient and four severe complications (severe bleeding, respiratory failure, deep venous thrombosis and gastrointestinal prophylaxis, and nicked renal vein and aborted procedure) were reported in two S-LLIF patients.
\end{abstract}

Conclusions: Preliminary evidence suggests that minimally invasive lateral interbody fusion with direct psoas visualization may reduce the risk for severe procedural complications.

Keywords: Fusion, Lateral, Lumbar, Minimally invasive, Psoas

\section{Background}

Fusion surgery is a viable treatment option for reducing pain and improving function in patients with chronic low back pain refractory to nonsurgical care. Several open and minimally invasive lumbar fusion approaches are available to the spine surgeon including anterior lumbar interbody fusion (ALIF), posterior lumbar interbody fusion (PLIF), and transforaminal lumbar interbody fusion (TLIF). Iatrogenic injury is an inherent risk of these procedures. ALIF endangers major organs and blood vessels [1-3], while PLIF [4-7] and TLIF [8,9] can cause musculoligamentous injury, nerve root injury, and spinal fluid leakage.

\footnotetext{
* Correspondence: jonblock@jonblockgroup.com

${ }^{4}$ The Jon Block Group, 2210 Jackson Street, Suite 401, San Francisco, CA 94115, USA

Full list of author information is available at the end of the article
}

Minimally invasive lateral approaches to the lumbar spine have been adopted to allow access to the intervertebral disc space while avoiding the complications associated with anterior or posterior approaches. The main limitation of lateral approaches is the potential for transient motor and sensory disturbances due to the inability to directly visualize the psoas muscle and the nerves of the lumbosacral plexus $[10,11]$. The wide variability in lumbar plexus anatomy complicates identification of a safe working zone under fluoroscopy [12], and access to L4-5 is further complicated by longer nerve roots [13] and significant narrowing of the working zone [14-16], resulting in higher complication rates [17]. The incidence of postoperative thigh pain or weakness with lateral interbody fusion using continuous neuromonitoring ranges from $67 \%-75 \%[10,18]$ with some cases lingering 
for 1 year or more [10]. Even in patients with no significant changes in electromyographic response, motor deficits following transpsoas fusion have been reported in $24 \%$ of patients [10]. Lateral approaches for lumbar interbody fusion that allow direct visualization of the psoas and surrounding nerves may improve patient safety.

\section{Methods}

This report describes a minimally invasive technique for lateral interbody fusion (DV-LLIF) that allows direct intraoperative visualization of the psoas and surrounding neurovasculature (VEO Lateral System, Baxano Surgical, Raleigh, NC, USA). This technique utilizes a radiolucent tubular retractor and an internal psoas retractor that allows a muscle-sparing approach while offering excellent visualization of the operative site [19].

With the patient in the lateral decubitus position, true anteroposterior and lateral fluoroscopic images are obtained. A 3-cm anteroposterior incision is made over the center of the disc space, and dissection is continued deep to the external oblique fascia. The muscle layers of the abdominal wall are longitudinally separated with blunt instruments to access the retroperitoneal space. The surgical corridor is then established using sequential blunt dilators inserted through the retroperitoneal space and onto the surface of the psoas muscle. Once correct retractor position is confirmed with fluoroscopy, a radiolucent tube (Figure 1) is inserted, the dilators are removed, and a lateral fluoroscopic image confirms correct positioning over the disc space (Figure 2). At this point in the procedure, the psoas muscle and surrounding nerves can be directly visualized (Figure 3). Dissection continues in the anteroposterior direction to the level of the disc (Figure 4). The nerve roots may be directly visible through the tube prior to and during dissection. Depending of the level treated, the sensory root may be observed traversing the surface of the muscle, while the motor

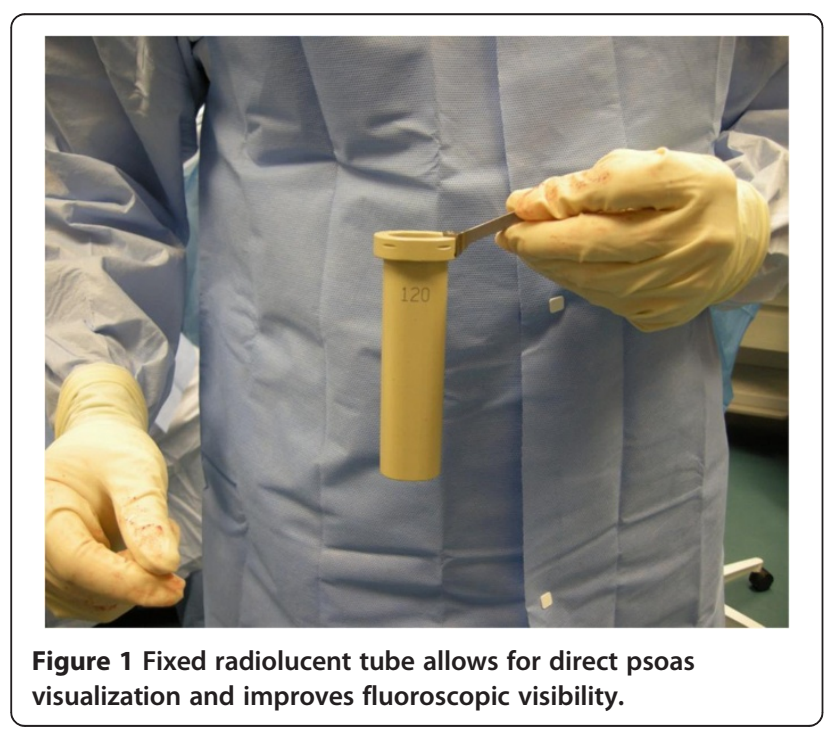

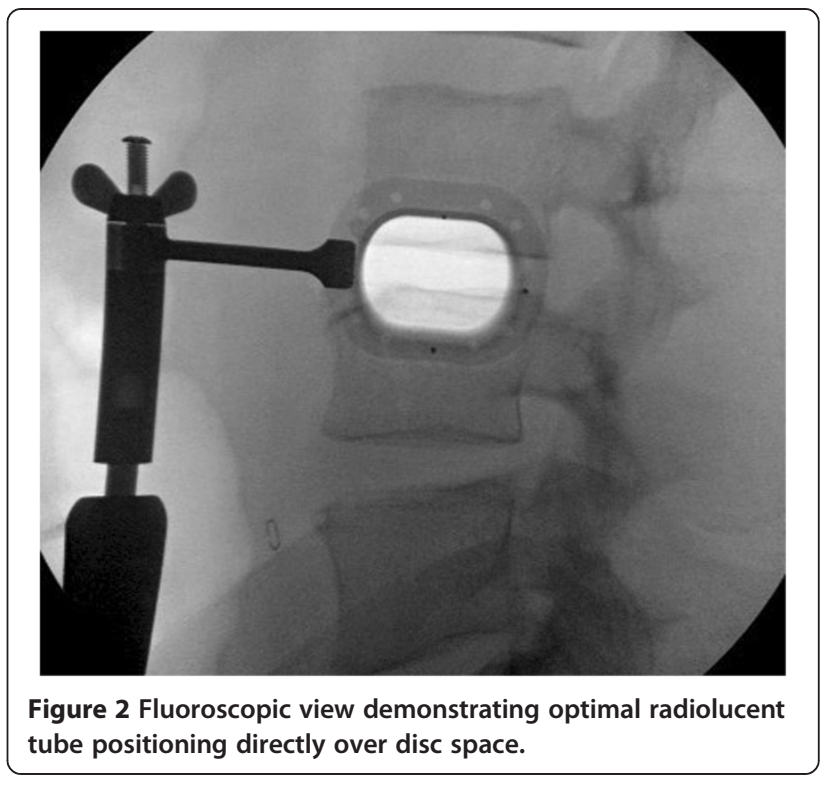

roots are most commonly observed to the posterior. Two hand-held blades and an inner sleeve are used to retract the psoas muscle to the level of the disc an annulotomy is performed (Figure 5). Discectomy and endplate preparation are then completed using standard instruments. Autogenous bone graft material is packed inside a PEEK implant, which is inserted into the disc space. Final anteroposterior and lateral images are taken, all instrumentation is removed, and the wound is closed in the standard fashion. The technique is indicated for use with supplemental fixation devices, which may be selected at the surgeon's discretion.

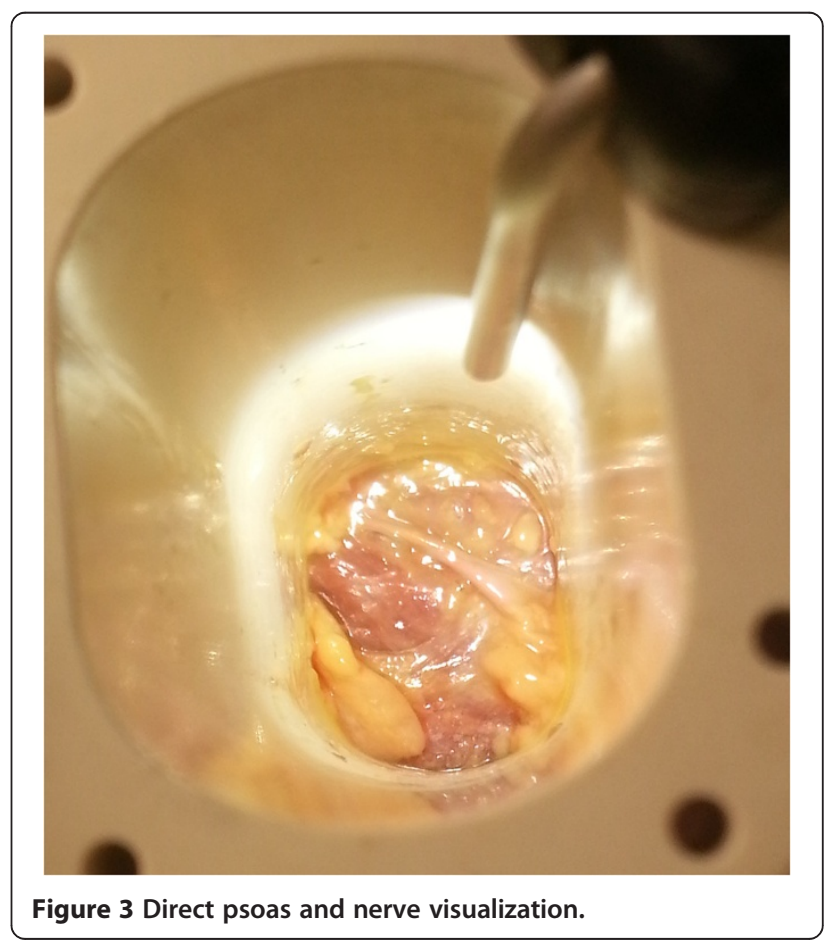




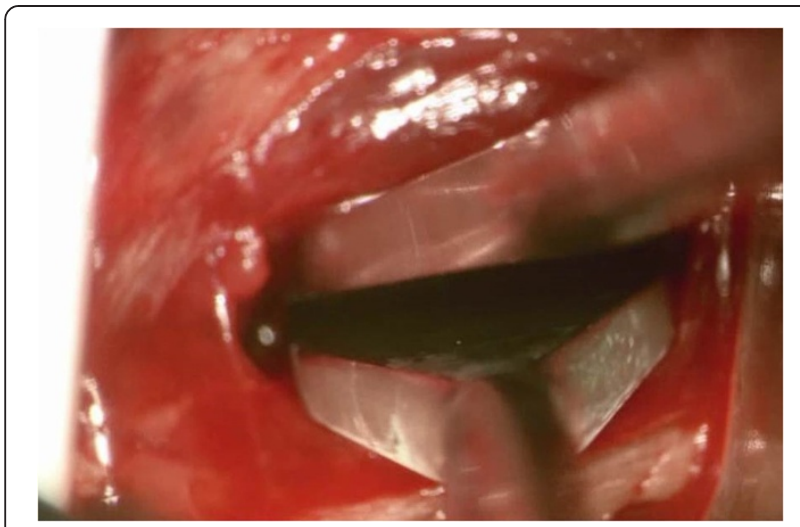

Figure 4 Manual psoas dissection.

\section{Results and discussion}

The evidence that direct visualization of the psoas during LLIF reduces iatrogenic complications is limited, yet promising. We retrospectively reviewed 34 cases (Table 1) treated with DV-LLIF $(n=19)$ or (S-LLIF, $n=15)$ for degenerative disc disease. Following IRB approval at each center, retrospective chart reviews were performed at four centers with experience in both techniques for consecutive patients treated with DV-LLIF or S-LLIF between October 2011 and August 2013.

All complications, regardless of severity, were recorded into a pre-defined database (Table 2). Complications were categorized as mild, moderate, or severe. A mild complication was transient or caused mild discomfort, required no intervention/therapy, and did not interfere with the normal activities. A moderate complication caused some limitation in activity, which may have required assistance, and no or

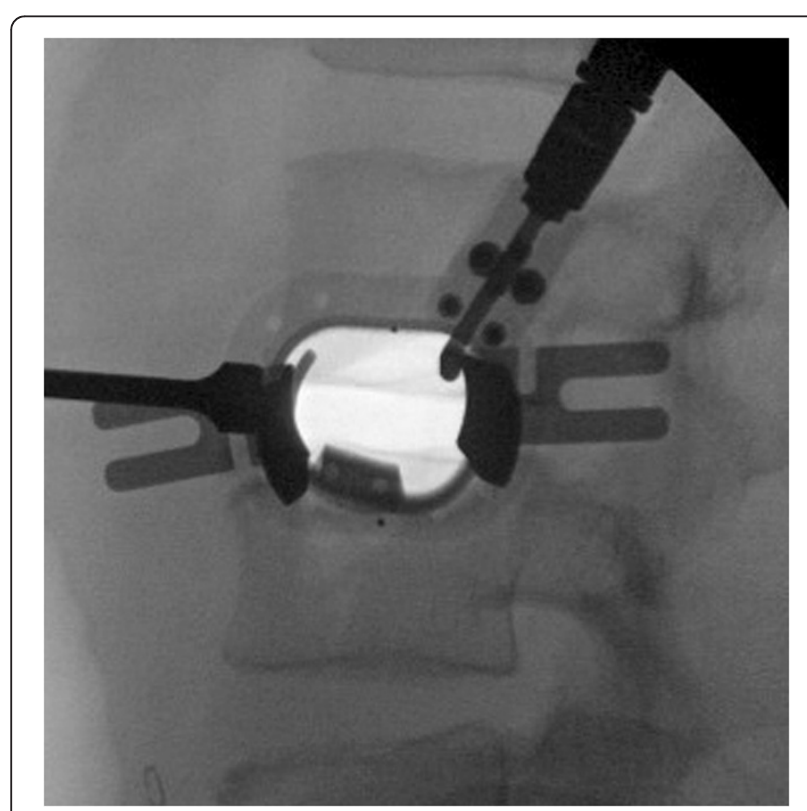

Figure $\mathbf{5}$ Lateral fluoroscopic image of fully-assembled DV-LIF retractor.
Table 1 Baseline characteristics of 34 cases treated with DV-LLIF or S-LLIF

\begin{tabular}{lccc}
\hline Variable & $\begin{array}{c}\text { DV-LLIF } \\
\boldsymbol{n = 1 9}\end{array}$ & $\begin{array}{c}\text { S-LLIF } \\
\boldsymbol{n}=15\end{array}$ & $\boldsymbol{P}$ value \\
\hline Male gender, $n(\%)$ & $6(32)$ & $11(73)$ & $0.04^{\mathrm{a}}$ \\
Age, year, median $(\mathrm{IQR})$ & $65(53-70)$ & $66(53-74)$ & $0.87^{\mathrm{b}}$ \\
Body mass index, $\mathrm{kg} / \mathrm{m}^{2}$, median $(\mathrm{IQR})$ & $29(23-34)$ & $27(22-29)$ & $0.27^{\mathrm{b}}$ \\
\hline
\end{tabular}

${ }^{\mathrm{a}}$ Fisher's exact test; ${ }^{\mathrm{b}}$ Mann-Whitney $U$ test. $I Q R$ interquartile range.

minimal intervention/therapy was required. A severe complication caused marked limitation in activity, interrupted usual daily activity, and required medical intervention/ therapy.

There were 29 complications (median, 1.0 per patient) with DV-LLIF and 20 (median, 1.0 per patient) complications with S-LLIF. Postoperative sensory deficits were reported in eight (42\%) and seven (47\%) patients, respectively. Thigh pain or numbness was reported in eight (42\%) and five (33\%) patients, respectively. The percentage of overall complications directly attributable to the procedure was $69 \%$ with DV-LLIF and $83 \%$ with S-LLIF. A severe complication (back pain at day 70) was reported in one (5\%) patient with DV-LLIF, while four severe complications (severe bleeding, respiratory failure, deep venous thrombosis and gastrointestinal prophylaxis, and nicked renal vein and aborted procedure) were reported in two (13\%) patients treated with S-LLIF. Median time to complication was 30 (IQR, 11-61) days with DV-LLIF and 24 (0-75) days with S-LLIF.

The reductions in procedural risks with DV-LLIF have been reported by others. Hardenbrook [20] reported no nerve, vascular, or intra-abdominal injuries and one case of transient lower extremity weakness in 65 subjects (87 levels). Fleischer and colleagues [21] treated 27 patients with LLIF using direct visualization. All cases were technically successful and patients treated had lower complication rates compared to open fusion controls, including overall complications, pain, paresthesias, motor weakness, and need for thigh anesthesia.

Table 2 Complications in 34 cases treated with DV-LLIF or S-LLIF

\begin{tabular}{lccc}
\hline Complication data & $\begin{array}{c}\text { DV-LLIF } \\
\boldsymbol{n = 1 9}\end{array}$ & $\begin{array}{l}\text { S-LLIF } \\
\boldsymbol{n = 1 5}\end{array}$ & $\boldsymbol{P}$ value \\
\hline $\begin{array}{l}\text { Patients with any } \\
\text { complication, } n \text { (\%) }\end{array}$ & $15(79)$ & $12(80)$ & $0.64^{\mathrm{a}}$ \\
$\begin{array}{l}\text { Complications per patient, } \\
\text { median (IQR) }\end{array}$ & $1.0(0.5-1.5)$ & $1.0(1.0-2.0)$ & $0.25^{\mathrm{b}}$ \\
$\begin{array}{l}\text { Severity, } n \\
\quad \text { Mild }\end{array}$ & 19 & & \\
$\quad$ Moderate & 9 & 11 & \\
$\quad$ Severe & 1 & 5 & $0.10^{\mathrm{a}, \mathrm{c}}$ \\
\hline
\end{tabular}

${ }^{\mathrm{a}}$ Fisher's exact test; ${ }^{\mathrm{b}}$ Mann-Whitney $U$ test; ${ }^{\mathrm{c}} P$ value calculated for severe complications. IQR interquartile range. 
Although this research was limited by a small sample size, the thoroughness of complication reporting is a strength of the paper since we reported all complications, regardless of the severity. This is likely why the complication rates are higher than those typically reported for lumbar interbody fusion. Considering that only 'severe' complications required treatment, the reported rates of $5 \%$ for DV-LLIF and 13\% for S-LLIF are comparable to previous literature $[17,22]$.

\section{Conclusions}

Based on preliminary data, a minimally invasive LLIF technique that allows direct visualization of the operative field may reduce the risk for severe procedural complications. Additionally, direct visualization of the operative field allows the surgeon the opportunity to abort the procedure if the surgical corridor involves unanticipated anatomical obstructions. As with any surgical procedure, spine surgeons must be intimately familiar with relevant anatomy, and thorough training and experience with the transpsoas approach are paramount to achieving optimal clinical results.

\section{Nomenclature}

LLIF = lateral lumbar interbody fusion

\section{Study groups}

Direct visualization LLIF (DV-LLIF) vs. standard LLIF (S-LLIF)

\section{Competing interests}

LEM and JEB received financial support from Baxano Surgical, Inc. for assistance with manuscript development.

\section{Authors' contributions}

LM wrote the first manuscript draft. PY, KR, RV, and JB provided critical review and revision. All authors read and approved the final manuscript.

\section{Author details}

${ }^{1}$ Memorial Orthopedic Surgical Group, 2760 Atlantic Ave, Long Beach, CA 90806, USA. University Orthopaedic Associates, 611 Northern Blvd, Suite 200, Great Neck, NY 11021, USA. ${ }^{3}$ Miller Scientific Consulting, Inc, 1854 Hendersonville Road, \#231, Asheville, NC 28803, USA. ${ }^{4}$ The Jon Block Group, 2210 Jackson Street, Suite 401, San Francisco, CA 94115, USA.

Received: 31 December 2013 Accepted: 18 March 2014 Published: 26 March 2014

\section{References}

1. Baker JK, Reardon PR, Reardon MJ, Heggeness MH: Vascular injury in anterior lumbar surgery. Spine (Phila Pa 1976) 1993, 18:2227-2230.

2. Rajaraman V, Vingan R, Roth P, Heary RF, Conklin L, Jacobs GB: Visceral and vascular complications resulting from anterior lumbar interbody fusion. J Neurosurg 1999, 91:60-64.

3. Garg J, Woo K, Hirsch J, Bruffey JD, Dilley RB: Vascular complications of exposure for anterior lumbar interbody fusion. J Vasc Surg 2010, 51:946-950. Discussion 950.

4. Moskowitz A: Transforaminal lumbar interbody fusion. Orthop Clin North Am 2002, 33:359-366.

5. Cho KJ, Suk SI, Park SR, Kim JH, Kim SS, Choi WK, Lee KY, Lee SR: Complications in posterior fusion and instrumentation for degenerative lumbar scoliosis. Spine (Phila Pa 1976) 2007, 32:2232-2237.
6. Hosono N, Namekata M, Makino T, Miwa T, Kaito T, Kaneko N, Fuji T: Perioperative complications of primary posterior lumbar interbody fusion for nonisthmic spondylolisthesis: analysis of risk factors. J Neurosurg Spine 2008, 9:403-407.

7. Scaduto AA, Gamradt SC, Yu WD, Huang J, Delamarter RB, Wang JC: Perioperative complications of threaded cylindrical lumbar interbody fusion devices: anterior versus posterior approach. J Spinal Disord Tech 2003, 16:502-507.

8. Rihn JA, Patel R, Makda J, Hong J, Anderson DG, Vaccaro AR, Hilibrand AS, Albert TJ: Complications associated with single-level transforaminal lumbar interbody fusion. Spine J 2009, 9:623-629.

9. Peng CW, Yue WM, Poh SY, Yeo W, Tan SB: Clinical and radiological outcomes of minimally invasive versus open transforaminal lumbar interbody fusion. Spine (Phila Pa 1976) 2009, 34:1385-1389.

10. Cummock MD, Vanni S, Levi AD, Yu Y, Wang MY: An analysis of postoperative thigh symptoms after minimally invasive transpsoas lumbar interbody fusion. J Neurosurg Spine 2011, 15:11-18.

11. Houten JK, Alexandre LC, Nasser R, Wollowick AL: Nerve injury during the transpsoas approach for lumbar fusion. J Neurosurg Spine 2011, 15:280-284

12. Guerin P, Obeid I, Bourghli A, Masquefa T, Luc S, Gille O, Pointillart V, Vital JM: The lumbosacral plexus: anatomic considerations for minimally invasive retroperitoneal transpsoas approach. Surg Radiol Anat 2011, 34:151-157.

13. Hasegawa T, Mikawa $Y$, Watanabe R, An HS: Morphometric analysis of the lumbosacral nerve roots and dorsal root ganglia by magnetic resonance imaging. Spine (Phila Pa 1976 1996, 21:1005-1009.

14. Guerin P, Obeid I, Gille O, Bourghli A, LuC S, Pointillart V, Cursolle JC, Vital JM: Safe working zones using the minimally invasive lateral retroperitoneal transpsoas approach: a morphometric study. Surg Radiol Anat 2011, 33:665-671.

15. Kepler CK, Bogner EA, Herzog RJ, Huang RC: Anatomy of the psoas muscle and lumbar plexus with respect to the surgical approach for lateral transpsoas interbody fusion. Eur Spine J 2011, 20:550-556.

16. Regev GJ, Chen L, Dhawan M, Lee YP, Garfin SR, Kim CW: Morphometric analysis of the ventral nerve roots and retroperitoneal vessels with respect to the minimally invasive lateral approach in normal and deformed spines. Spine (Phila Pa 1976) 2009, 34:1330-1335.

17. Rodgers WB, Gerber EJ, Patterson J: Intraoperative and early postoperative complications in extreme lateral interbody fusion: an analysis of 600 cases. Spine (Phila Pa 1976) 2011, 36:26-32.

18. Youssef JA, McAfee PC, Patty CA, Raley E, DeBauche S, Shucosky E, Chotiku $\mathrm{L}$ : Minimally invasive surgery: lateral approach interbody fusion: results and review. Spine (Phila Pa 1976) 2010, 35:S302-S311.

19. Hardenbrook MA, Miller LE, Block JE: TranS1 VEO system: a novel psoas-sparing device for transpsoas lumbar interbody fusion. Med Devices (Auckl) 2013, 6:91-95.

20. Hardenbrook MA: \#218 A new approach to lateral lumbar interbody fusion with one-year follow-up. In 12th Annual Conference of ISASS 2012: March 20-23 2012; Barcelona.

21. Fleischer $G$, Kearns J, Bellisle M, Nguyen T: Direct visualization of the lumbar nerves during transpsoas approach to lateral interbody lumbar fusion significantly reduces nerve injury and postoperative thigh symptoms. In 13th Annual Conference of ISASS 2013: April 3-5 2013; Vancouver. A-506-0000-00528.

22. Knight RQ, Schwaegler $P$, Hanscom D, Roh J: Direct lateral lumbar interbody fusion for degenerative conditions: early complication profile. J Spinal Disord Tech 2009, 22:34-37.

doi:10.1186/1749-799X-9-20

Cite this article as: Yuan et al:: Minimally invasive lateral lumbar interbody fusion with direct psoas visualization. Journal of Orthopaedic surgery and Research 2014 9:20. 